\title{
Glutathione $S$ transferase theta1 and mu1 gene polymorphisms and phenotypic expression of asthma in Egyptian children: a case-control study
}

Nihal El Rifai ${ }^{1,3^{*}}$, Nadia Moustafa', Nelly Degheidy ${ }^{1}$ and Manal Wilson ${ }^{2}$

\begin{abstract}
Background: Asthma is the result of a complex interaction between environmental factors and genetic variants that confer susceptibility. The glutathione S-transferases (GSTT1 and GSTM1) are phase II enzymes thought to protect the airways from oxidative stress. Few and contradictory data are available on the association between asthma development and GSTT1 and GSTM1 polymorphisms in different ethnic groups. The current study aimed to investigate whether these polymorphisms are associated with asthma development in the Egyptian population.

Methods: The cross-sectional study was performed on 94 asthmatic children $6-12$ yrs and 90 matched healthy controls. Candidates were subjected to clinical evaluation and measurement of absolute blood eosinophilic count, total serum IgE, and GSTT1 and GSTM1 genotype by multiplex PCR technique.

Results: The results for GSTT1 null genotype were $87.2 \%$ and $97.2 \%$ for asthmatic children and controls respectively and showed to be significantly more in controls ( $P=0.007$, OR:0.683, Cl: $0.034-0.715$ ). The results for GSTM1 null genotype were $50 \%$ and $61.1 \%$ for asthmatic children and controls respectively and showed to be nonsignificant ( $p=0.130$, OR: 1.000, Cl: 0.54- 1.86). Also, no association was detected between GSTT1 and GSTM1 polymorphisms and atopic conditions or asthma severity.

Conclusion: The significant detection of GSTT1 null genotype more in controls than in asthmatics with no association with other atopic manifestations or asthma severity and the lack of association detected between GSTM1 polymorphism in relation to asthma, atopy or asthma severity confirm the uncertain role of those genes in the development of asthma.
\end{abstract}

Keywords: Asthma, Children, Egyptian, Glutathione S-transferase, Polymorphism

\section{Introduction}

Asthma is a disorder of the airways characterized by several symptoms such as airflow obstruction, airway inflammation, and hyper responsiveness [1]. The study of genetic factors involved in complex pathologies such as asthma is arduous, not only because of human genetic variability, or incomplete penetrance, but also because, in complex disease studies, the importance and strength of gene to gene and gene to environment interactions need to be considered [2]. The prevalence of candidate gene polymorphisms for asthma varies considerably worldwide, and accordingly, ethnicity should be considered as a

\footnotetext{
* Correspondence: nihal-r@hotmail.com

'Department of Pediatrics, Faculty of Medicine, Cairo University, Giza, Egypt ${ }^{3}$ New University Children's Hospital (Abu El Reish), 4 - Gamal Salem St. Doki, Cairo, Egypt

Full list of author information is available at the end of the article
}

factor that might act on and influence asthma development. Previous data based on intra- and inter-population frequency differences suggest that the association between a given genetic polymorphism and asthma cannot be extrapolated from one ethnic group to another [3].

Phase II detoxification enzymes, particularly classes of GSTs, play an important role in inflammatory responses triggered by xenobiotic or reactive oxygen compounds [4]. The GSTM1 and GSTT1 are two important phase II enzymes that protect the airways from oxidative stress [5]. They utilize as substrates a wide variety of products of oxidative stress [6]. The inability of GST variant enzymes to detoxify reactive oxygen species contributes to the activation of the inflammatory process, bronchoconstriction, and the exacerbation of asthma symptoms [4]. In particular, GSTM1 and GSTT1 null polymorphisms 
may influence the pathogenesis of respiratory diseases. Numerous studies have documented associations between genes implicated in the oxidative stress response and respiratory phenotypes, but data suggest that they may not be consistent across ethnic groups owing to differences in intra- and inter-ethnic allele frequencies [7].

The aim of the current study was to detect the presence of an association between GSTM1 and GSTT1 polymorphisms and asthma, atopy or asthma severity.

\section{Methods}

The present cross-sectional case-control study is conducted on a group of Egyptian asthmatic children (n: 94) and their age and sex matched healthy controls (n: 90) from September 2012 to June 2013. Patients were recruited from the allergy clinic of Cairo university specialized pediatric hospital where they were following up after being diagnosed according to GINA guidelines criteria of asthma classification [8]. All patients were subjected to a questionnaire containing a detailed history and clinical examination with emphasis on age, sex, family history, presence of atopic manifestations and asthma severity classification according to GINA Guidelines [8]. The following investigations were performed for all patients and controls.

\section{Total immunoglobulin E (IgE) and Prick test assays}

Atopy was defined by a positive history of atopic manifestations, positive skin prick test (wheal diameter $\geq 3 \mathrm{~mm}$ ) to at least one of the following aeroallergens (Dermatophagoides Farinae, hay Dust, Dermato-pteronyssinus, Alternaria Tenuis, Moulds II, Candida Albicans, Cat epithelia, Hen's egg, Dog epithelia, Grasses/cereals, Cow's milk in the presence of positive histamine control and negative physiological saline control using reagents obtained from Allergopharma D21462 Reinbek, Germany) and by the quantitative determination of human total IgE in serum using the DiaMed Eurogen IgE quantitative technique which is a monoclonal antibody based enzyme immunoassay (Positive values were taken to be $\geq 200 \mathrm{IU} / \mathrm{ml}$ ). Among the 94 asthmatic children there were 67 atopic and 27 nonatopic children.

\section{Pulmonary function tests assay}

Spirometric measurements using a Jaeger Master Screen Spirometry system (Jaeger Co) were done and included forced vital capacity (FVC), forced expiratory volume in $1 \mathrm{~s}$ (FEV1), and forced expiratory flow between $25 \%$ and 75\% expired volume (FEF25-75). Short-acting bronchodilators were stopped at least $8 \mathrm{~h}$ before the test. All pulmonary function data were collected at a single visit. A minimum of 3 results within 10\% of each other were recorded, and the result with the highest FEV1 was analyzed. The participants were not suffering from asthma exacerbations or other acute illnesses at the time of the measurement of pulmonary function. The lung function test results were expressed as a percentage of that predicted.

The personal, family, medical history and clinical presentation of controls were free of any atopic or allergic diseases with negative skin prick tests, normal total IgE values, normal lung function tests.

\section{Genotyping of GSTT1 and GSTM1}

$100 \mathrm{ng}$ of DNA were amplified in a-50 ul multiplex reaction mixture containing $0.90 \mathrm{pmol}$ of each of the following GSTT1 primers (GSTT1-Forward: GAACTCCCTG AAAAGCTAAAGC and GSTT1-Reverse: GTTGGGCT CAAATATACGGTGG) and GSTM1 primers (GSTM1Forward: TTCCTCACTGGTCCTCACATCTC and GST M1-Reverse: TCACCGGATCATGGCCAGCA). As an internal control, the beta-globulin gene was also amplified using the following amplification sequence (Forward primer: GCCCTCTGCTAACAAGTCCTAC and Reverse primer: GCCCTAAAAAGAAAATCGCCAATC) [9]. The amplification reaction consisted of 0.9 pmol of each primer added to $12.5 \mathrm{u}$ PCR master mix which contains $3.5 \mathrm{mM} \mathrm{MgCl} 2,200 \mathrm{uM}$ dNTPs, 5 ul 10X PCR buffer, and 2U TaqDNA polymerase (Fermentas).

The PCR protocol included: initial melting temperature of $94^{\circ} \mathrm{C}$ ( 5 minutes), amplification by 35 cycles of 20 seconds at $94^{\circ} \mathrm{C}, 20$ seconds at $64^{\circ} \mathrm{C}$, and 30 second at $72^{\circ} \mathrm{C}$ ) then final extension at $72^{\circ} \mathrm{C}$ for 7 minutes. Analysis of PCR products on agarose gels where a fragment of $215 \mathrm{pb}$ indicated the presence of GSTM1, a fragment of $480 \mathrm{pb}$ indicated the presence of GSTT1 and a fragment of 280 $\mathrm{pb}$ indicated the positive internal control $\mathrm{B}$ globulin. The subjects were classified as either $(+)$, when at least one specimen of the gene was detected, or (-) when they showed a null genotype.

\section{Ethical considerations}

The aim and nature of the study was explained for each candidate and/or parent before inclusion. An informed written consent was obtained from parents/surrogates before enrollment. Children old enough were asked for consent. Cairo University Hospital Research Ethical Committee approved the work and it conforms to the provisions of the Declaration of Helsinki in 1995 (as revised in Seoul 2008).

\section{Statistical analysis}

Data were statistically described in terms of mean \pm standard deviation $( \pm \mathrm{SD})$, median and range, or frequencies (number of cases) and percentages when appropriate. Comparison of numerical variables between the study groups was done using Student's $t$ test for independent samples when comparing 2 groups of normally distributed data and Mann Whitney test when comparing 2 groups of non- 
normal data. Kruskal Wallis test with posthoc multiple 2group comparisons was used to compare numerical data between more than 2 groups. For comparing categorical data, Chi square $\left(x^{2}\right)$ test was performed. Exact test was used instead when the expected frequency is less than 5 . Odds ratio with its $95 \% \mathrm{CI}$ was used to present the relation between haplotypes in cases and controls. Haldane modification was used when the occurrence of any haplotypes was zero. $p$ values less than 0.05 was considered statistically significant. All statistical calculations were done using computer programs SPSS (Statistical Package for the Social Science; SPSS Inc., Chicago, IL, USA) version 15 for Microsoft Windows.

\section{Results}

We investigated 94 children with asthma, approximately $67 \%$ of whom were atopic, and 90 age and sex matched healthy controls. Table 1 summarizes the characteristics of both groups. Age was found to be significantly higher in controls $(p=0.025)$. Male sex was found to be significantly higher in asthmatics $(p=0.019)$. No significant differences were found between asthmatic patients and healthy controls for any of the other characteristics analyzed. Data regarding the genotype frequencies of the
GSTT1 and GSTM1 homozygous deletions in asthmatics and controls are also shown in Table 1. GSTT1 null genotype was found to be significantly higher in controls than in asthmatics $(\mathrm{p}=0.007, \mathrm{CI}=0.683, \mathrm{OR}=0.034-0.714)$. No significant difference in the genotype distribution of the GSTM1 gene was found between asthmatics and controls. No significant differences in the genotype distributions of the GSTT1 or GSTM1 genes were found between atopic and nonatopic asthmatics ( $\mathrm{p}=0.706$ and 0.820 respectively) as shown in Table 2. Also, no significant differences in the genotype distributions of the GSTT1 or GSTM1 genes were found between asthmatics stratified by disease severity ( $\mathrm{p}=0.236$ and 0.892 respectively) as shown in Table 3.

\section{Discussion}

It was recently recognized that GSTs play an active role in oxidative defenses and members of this superfamily may be determinants of respiratory health [10]. The presence of the GSTT1 null polymorphism was $87.2 \%$ and $97.2 \%$ in asthmatics and controls respectively and the results showed to be significantly higher in controls $(\mathrm{P}=0.007$, OR:0.683, CI: $0.034-0.715)$. The results for GSTM1 were $50 \%$ and $61.1 \%$ respectively and showed to be nonsignificant ( $\mathrm{p}=0.130$, OR: $1.000, \mathrm{CI}$ : 0.54- 1.86).

Table 1 Characteristics and genotype distributions in asthmatics and controlsa

\begin{tabular}{|c|c|c|c|c|c|}
\hline & Asthmatics & Controls & P-value & OR & $95 \% \mathrm{Cl}$ \\
\hline Age (Mean $\pm S D$ ), years & $7.65 \pm 1.916$ & $8.27 \pm 1.785$ & $0.025^{*}$ & - & - \\
\hline Sex & & & & - & - \\
\hline Male & $62(66 \%)$ & $44(48.9 \%)$ & $0.019^{*}$ & & \\
\hline Female & $32(34 \%)$ & $46(51.1 \%)$ & & & \\
\hline Spirometry & & & - & - & - \\
\hline FEV1 (\%predicted)** & $97 \pm 6.2$ & - & & & \\
\hline FVC (\%predicted) ${ }^{* * *}$ & $96 \pm 8.2$ & & & & \\
\hline \multicolumn{6}{|l|}{ Disease severity } \\
\hline Mild persistent & $21(22 \%)$ & - & - & - & - \\
\hline Moderate persistent & $36(38.3 \%)$ & & & & \\
\hline Severe persistent & 37 (39.3\%) & & & & \\
\hline \multicolumn{6}{|l|}{ Atopy } \\
\hline Atopic & $67(71.3 \%)$ & & - & - & - \\
\hline Non atopic & $27(28.7 \%)$ & $90(100 \%)$ & & & \\
\hline Passive smoking exposure & $39(41.5 \%)$ & $28(31.1 \%)$ & 0.168 & - & - \\
\hline \multicolumn{6}{|l|}{ GSTT1 } \\
\hline Null & $82(87.2 \%$ & $88(97.8 \%)$ & & & \\
\hline Present & $12(12.8 \%)$ & $2(2.2 \%)$ & $0.007^{*}$ & 0.683 & $0.034-0.715$ \\
\hline \multicolumn{6}{|l|}{ GSTM1 } \\
\hline Null & $47(50 \%)$ & $55(61.1 \%)$ & & & \\
\hline Present & 47 (50\%) & 35 (38.9\%) & 0.130 & 1.000 & $0.539-1.857$ \\
\hline
\end{tabular}

aData are expressed as no. (\%) of patients unless otherwise indicated.

*P-value less than 0.05 is considered statistically significant.

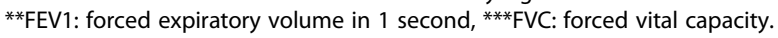


Table 2 Genotype distributions in atopic asthmatics and non-atopic asthmatics ${ }^{a}$

\begin{tabular}{lccc}
\hline & $\begin{array}{c}\text { Atopic asthmatics } \\
\mathbf{n = 6 7}(\%)\end{array}$ & $\begin{array}{c}\text { Non-atopic asthmatics } \\
\mathbf{n = 2 7}(\%)\end{array}$ & P-value \\
\hline GSTT1 & & & \\
Null & $59(88.1 \%)$ & $23(85.2 \%)$ & 0.706 \\
Present & $8(11.9 \%)$ & $4(14.8 \%)$ & \\
GSTM1 & & & \\
Null & $33(49.3 \%)$ & $14(51.9 \%)$ & 0.820 \\
Present & $34(50.7 \%)$ & $13(48.1 \%)$ &
\end{tabular}

aData are expressed as no. (\%) of patients unless otherwise indicated.

A systematic review and meta-analysis for the effects of GST genes on asthma demonstrated that a large Avon Longitudinal Study of Parents and Children found a protective effect on asthma of the GSTT1 null allele in mothers (OR: 0.71 ; 95\% CI: $0.57-0.90$ and 0.84; $0.63-1.12$, for heterozygotes and null homozygotes, respectively, compared with wild-type homozygotes) and children (0.91; 0.76-1.11 and 0.89; 0.70-1.13) [11]. No association of the disease with GSTT1 null genotype was noted by several studies in different populations [2,12-20]. However, in contrary to our findings an increased risk was seen in individuals with this genotype in some studies [3,21-24]. Similarly, a study performed on Egyptian population in Zagazig -located in northern Egypt- showed that asthmatic children had a significant lower prevalence of GSTT1 null genotype than the control group $(P=0.003)$. However, a higher prevalence of the GSTM1 null genotype was observed in the asthmatic group [25]. As our study was performed in Cairo- the capital of Egypt located in the centre- the enrolled patients were referred from upper Egypt that's why a difference in GSTM1 null genotype frequencies among asthmatics and controls in the two studies.

In agreement with the current study results, no association of the disease with GSTM1 null genotype was noted by several studies in different populations $[2,12-16,18]$. However, an increased risk was seen in individuals with

Table 3 Genotype distributions in asthmatics stratified by disease severity ${ }^{a}$

\begin{tabular}{lcccc}
\hline & $\begin{array}{c}\text { Mild } \\
\text { persistent } \\
\mathbf{n = 2 4}(\%)\end{array}$ & $\begin{array}{c}\text { Moderate } \\
\text { persistent } \\
\mathbf{n = 3 6}(\%)\end{array}$ & $\begin{array}{c}\text { Severe } \\
\text { persistent } \\
\mathbf{N = 3 4}(\%)\end{array}$ & P- value \\
\hline GSTT1 & & & & \\
Null & $21(87.5 \%)$ & $29(80.6 \%)$ & $32(94.1 \%)$ & \\
Present & $3(12.5 \%)$ & $7(19.4 \%)$ & $2(5.9 \%)$ & 0.236 \\
GSTM1 & & & & \\
Null & $12(50 \%)$ & $19(52.8 \%)$ & $16(47.1 \%)$ & \\
Present & $12(50 \%)$ & $17(47.2 \%)$ & $18(52.9 \%)$ & 0.892 \\
\hline
\end{tabular}

${ }^{a}$ Data are expressed as no. (\%) of patients unless otherwise indicated. this genotype in some reports $[3,17,19-24]$. The fact that asthma pathogenesis is a result of interactions between multiple genetic and environmental factors highlight that exposure to environmental chemical agents may explain the differences encountered.

A recent study done in Italy for asthmatic adultswhich revealed no association for both null genotypes with the disease- stated that the differences in the prevalence of asthma in different ethnic groups reflect and highlight genetic variances with a significant coverage of environmental conditions. The study declared that rapid change in asthma prevalence is not linked to genetic changes in populations because these mechanisms are too slow to explain this scenario and the effect of environmental exposures and interactions between genetic factors and environmental conditions are still a matter of debate [26].

The current study revealed that the frequencies of GSTT1 and GSTM1 null genotypes in controls were $97.8 \%$ and $60.1 \%$ respectively. The frequencies previously reported in the Egyptian population (15\% and $44 \%$ respectively among 34 subjects) [27] and in another study a higher frequencies was reported $(25.50 \%$ and $55.50 \%$ respectively) [28]. According to our results, the frequency of the GSTM1 null genotype (60.1\%) was slightly higher than the previous Egyptian studies, comparable to Caucasians (50.4\% -58\%), Europeans (39.00-62.00\%) and White Americans (35.00-62.00\%). However, the frequency of the GSTT1 null genotype (97.8\%) was extremely higher than the range of the previous Egyptian studies, Europeans (10.00-21.00\%), Africans (15.00-26.00\%) and Caucasian- Americans (10.00-36.00\%).

Differences in gene frequencies among various ethnic groups, may explain the differences encountered. A previous study that attempted to investigate the prevalence of important allelic variants of several genes including GST gene in the Egyptian population denoted that Egypt is unique geographically, as it is located centrally to the three continents of Africa, Europe and Asia, so its population is highly affected by the rapid pace of intercontinental transportation and large-scale immigration and that throughout history, the Greeks, Romans, Arabs, Turks, French and British have all ruled Egypt and mixed with its people, so that modern Egypt now is an amalgam of all these legacies. So, there is a considerable genetic admixture in the Egyptian population [28]. This genetic admixture explains more the differences encountered between the results of the current study done in Cairo- central Egypt- and that performed in Zagazig- northern Egypt.

The present study compared the GSTT1and GSTM1 null genotypes among asthmatic patients with the levels of asthma severity whether mild $(87.5 \%$ and $50 \%$ respectively), moderate ( $80.6 \%$ and $52.8 \%$ respectively) or severe persistent $(94.1 \%$ and $47.1 \%$ respectively) and it 
revealed no statistical significance ( $\mathrm{P}$ value: 0.236 and 0.892 respectively). These findings were supported by several studies $[12,14,15,29,30]$.

Regarding the genetic polymorphisms of GSTT1 and GSTM1 among atopic asthmatic patients and non-atopic asthmatics, no significant statistical difference in GSTT1 and GSTM1 polymorphisms was noted between the two groups ( $\mathrm{P}$ value: 0.706 and 0.820 respectively). In agreement with the current study, a study done on Egyptian population in zagazig announced that there is no significant association found between atopy and GSTT1 polymorphism. However, they found that the GSTM1 null genotype was significantly higher in atopic asthmatic cases than in nonatopic asthmatic subjects $(P=0.01)$ [25].

Comparison of our results with other studies indicates that GSTT1 and GSTM1 null genotypes were not universally associated with the asthma phenotypes. The genetic basis of asthma may differ between different ethnic groups. Future studies of large size should focus on interactions of GST genes with environmental oxidative exposures and with other genes involved in antioxidant pathways. Quality of study conduct and reporting need to be improved to increase credibility of the evidence accumulating over time.

\section{Competing interests}

The authors declare that they have no competing interests.

\section{Authors' contributions}

NMR, NMD and MMW - Designed, conducted and analyzed the study, NAM and NMR - Analyzed the data and drafted the manuscript. All authors revised and approved the manuscript.

\section{Funding}

The study was self-funded by authors.

\section{Author details}

${ }^{1}$ Department of Pediatrics, Faculty of Medicine, Cairo University, Giza, Egypt. Department of Clinical Pathology, Faculty of Medicine, Cairo University, Giza, Egypt. ${ }^{3}$ New University Children's Hospital (Abu El Reish), 4 - Gamal Salem St. Doki, Cairo, Egypt.

Received: 6 September 2013 Accepted: 19 February 2014

Published: 21 February 2014

\section{References}

1. Lemanske RF, Busse WW: Asthma: clinical expression and molecular mechanisms. J Allergy Clin Immunol 2010, 125:95-102.

2. Holla LI, Stejskalova A, Vasku A: Polymorphisms of the GSTM1 and GSTT1 genes in patients with allergic diseases in the Czech population. Allergy 2006, 61(2):265-267.

3. Hanene $C$, Jihene $L$, Jamel $A$, Kamel $H$, Agnès $H$ : Association of GST genes polymorphisms with asthma in Tunisian children. Mediators Inflamm 2007 37:1150-1157.

4. Goodrich GG, Goodman PH, Budhecha SK, Pritsos CA: Functional polymorphism of detoxifi cation gene NQO1 predicts intensity of empirical treatment of childhood asthma. Mutat Res 2009, 674:55-61.

5. Hayes JD, Flanagan JU, Jowsey IR: Glutathione transferases. Annu Rev Pharmacol Toxicol 2005, 45:51-88.

6. Hayes JD, Strange RC: Potential contribution of the glutathione S-transferase supergene family to resistance to oxidative stress. Free Radic Res 1995, 22:193-197.

7. Reddy P, Naidoo RN, Robins TG, Mentz G, London SJ, Li H, Naidoo R: GSTM1, GSTP1, and NQO1 polymorphisms and susceptibility to atopy and airway hyperresponsiveness among South African schoolchildren. Lung 2010, 188:409-414.

8. Global Strategy for the Diagnosis and Management of Asthma, Global Initiative for Asthma (GINA), revised 2010. http://www.ginasthma.com.

9. Sheikhha MH, Kalantar M, Tobal K, John A, Yin L: Glutathione S-transferase null genotype in acute myeloid leukemia. IJ/. 2005, 2:141-151.

10. Gilliland FD, Gauderman WJ, Vora H, Rappaport E, Dubeau L: Effects of glutathione-S-transferase M1, T1, and P1 on childhood lung function growth. AM J Respir Crit Care Med 2002, 166(5):710-716.

11. Minelli C, Granell R, Newson R, Rose-Zerilli M, Torrent M, Ring S, Holloway JW, Shaheen SO, Henderson JA: Glutathione-S-transferase genes and asthma phenotypes: a Human Genome Epidemiology (HuGE) systematic review and meta-analysis including unpublished data. Int $J$ Epidemiol 2010, 39:539-562.

12. Fre din MB, Bragina El, Ogorodova LM, Puzyrev VP: Polymorphism of the theta 1 and mu1 glutathione S-transferase genes (GSTT1, GSTM1) in patients with atopic bronchial asthma from the West Siberian region. Mol Biol 2002, 36(4):630-634.

13. Ercan H, Birben E, Dizdar EA, Keskin O, Karaaslan C, Soyer OU, Dut R, Sackesen C, Besler T, Kalaysi O: Oxidative stress and genetic and epidemiologic determinants of oxidants injury in childhood asthma. J Allergy Clin Immunol 2006, 118:1097-1104.

14. Mak JC, Ho SP, Leung HC, Cheung AH, Law BK, So LK, Chan JW, Chao CH, Lam WK, Ip MS, Chan-Yeung M: Relationship between glutathione s-transferase gene polymorphisms and enzyme activity in Hong Kong Chinese asthmatics. Clin Exp Allergy 2007, 37(8):1150-1157.

15. Salam MT, Lin PC, Avol EL, Gauderman WJ, Gilliland FD: Microsomal epoxide hydrolasem glutathione Stransferase P1, traffic and childhood asthma. Thorax 2007, 62(12):1050-1057.

16. Imboden M, Rochat $\mathrm{T}$, Brutsche MH, Schindler $\mathrm{C}$, Downs $\mathrm{SH}$, Gerbase MW, Burger W, Probst- Hensch NM, SAPALDIA Tea, APALDIA Team: Glutathione S-transferase genotype increases risk progression from bronchial hyperresponsiveness to asthma in adults. Thorax 2008, 63(4):322-328.

17. Islam T, Berhane K, McConnell R, Gauderman WJ, Avol E, Peters JM, Gilliland FD: Glutathione-S-transferase (GST) P1, GSTM1, exercise, ozone and asthma incidence in school children. Thorax 2009, 64(3):197-202

18. Castro-Giner F, Künzli N, Jacquemin B, Forsberg B, de Cid R, Sunyer J, Deborah J, David B, Danielle V, Dan N, González JR, Stefano G, Christer J, Josep-Maria A, Matthias W, Joachim H, Xavier E, Manolis K: Traffic-related air pollution, oxidative stress genes, and asthma (ECHRS). Environ Health Perspect 2009, 117:1919-1924.

19. Rogers AJ, Brasch-Andersen C, Ionita-Laza I, Murphy A, Sharma S, Klanderman BJ, Raby BA: The interaction of glutathione S-transferase M1-null variants with tobacco smoke exposure and the development of childhood asthma. Clin Exp Allergy 2009, 39:1721-1729.

20. Lima CS, Néri IA, Lourenço GJ, Faria IC, Ribeiro JD, Bertuzzo CS: Glutathione S-transferase mu 1 (GSTM1) and theta 1 (GSTT1) genetic polymorphisms and atopic asthma in children from Southeastern Brazil. Genet Mol Biol 2010, 33:438-441.

21. Ivaschenko TE, Sideleva OG, Baranov VS: Glutathione-S-transferase $\mu$ and theta gene polymorphisms as new risk factors of atopic bronchial asthma. J Mol Medic 2002, 80(1):39-43.

22. Brasch-Andersen C, Christiansen L, Tan Q, Haagerup A, Vestbo J, Kruse TA: Possible gene dosage effect of glutathione-S-transferases on atopic asthma: using real-time PCR for quantification of GSTM1 and GSTT1 gene copy numbers. Hum Mutat 2004, 24(3):208-214.

23. Saadat M, Saadat I, Saboori Z, Emad A: Combination of CC16, and GSTT1 genetic polymorphism is associated with asthma. J Allergy Clin Immunol 2006, 113:996-998.

24. Tamer L, MC a g, Ates NA, Yildirim H, Ercan B, Saritas E, Unlu A, Atik U: Glutathione-S-transferase gene polymorphisms (GSTT1, GSTM1 GSTP1) as increased risk factors for asthma. Respirology 2004 9(4):493-498.

25. Karam RA, Pasha HF, El-Shal AS, Rahman HM, Gad DM: Impact of glutathione-S-transferase gene polymorphisms on enzyme activity, lung function and bronchial asthma susceptibility in Egyptian children. Gene 2012, 497:314-319.

26. Piacentini S, Polimanti R, Moscatelli B, RE M, Manfellotto D, Fuciarelli M: Lack of association between GSTM1, GSTP1, and GSTT1 gene polymorphisms and asthma in adult patients from Rome, Central Italy. J Investig Allergol Clin Immunol 2012, 22(4):252-256. 
27. Abdel-Rahman SZ, El-Zein RA, Anwar WA, Au WW: A multiplex PCR procedure for polymorphic analysis of GSTM1 and GSTT1 genes in population studies. Cancer Lett 1996, 107:229-233.

28. Hamdy SI, Hiratsuka M, Narahara K, Endo N, El Enani M, Moursi N: Genotype and allele frequencies of TPMT, NAT2, GST, SULT1A1 and MDR- 1 in the Egyptian population. J Clin Pharmacol 2003, 55(6):560-569.

29. Sandford J, Chan HW, Wong GMK, Lai CKW, Chan-Yeung M: Candidate genetic polymorphisms for asthma in Chinese schoolchildren from Hong Kong. Intern J Tuberc Lung Dis 2004, 8(5):519-527.

30. Gattás GJ, Kato M, Soares-Vieira JA, Siraque MS, Kohler P, Gomes L, Rigo MA, Bydlowski SP: Ethnicity and glutathione S-transferase (GSTM1/GST1) polymorphisms in a Brazilian population. Braz J Med Biol Res 2004, 37:451-458.

\section{doi:10.1186/1824-7288-40-22}

Cite this article as: El Rifai et al:: Glutathione $\mathrm{S}$ transferase theta1 and mu1 gene polymorphisms and phenotypic expression of asthma in Egyptian children: a case-control study. Italian Journal of Pediatrics 2014 40:22.

\section{Submit your next manuscript to BioMed Central and take full advantage of:}

- Convenient online submission

- Thorough peer review

- No space constraints or color figure charges

- Immediate publication on acceptance

- Inclusion in PubMed, CAS, Scopus and Google Scholar

- Research which is freely available for redistribution 